\title{
Antibodies to rat Sertoli cell secretory proteins recognize antigenic sites in acrosome and tail of developing spermatids and sperm
}

\author{
ABRAHAM L. KIERSZENBAUM ${ }^{1} *$, HIROSHI UEDA ${ }^{1} \uparrow$, LIU PING $^{1} \uparrow$, MUNIR ABDULLAH ${ }^{1}$ and \\ LAURA L. TRES ${ }^{2, *}$ \\ Departments of ${ }^{1}$ Cell Biology and Anatomy and ${ }^{2}$ Pediatrics, School of Medicine, The Unversty of North Carolina at Chapel Hill, . NC 27599. \\ USA \\ - Present address: Department of Cell Biology and Anatomical Sciences, The City University of New York Medical School, \\ 138th Street and Convent Avenue, New York, NY 10031, USA \\ †Present address: University of Occupational and Environmental Health, Dept. of Anatomy, Kitakyushu 807, Japan \\ † Present address: Institutc of Basic Medical Sciences, Chinese Academy of Medıcal Sciences, Beijing, China
}

\begin{abstract}
Summary
Polyclonal antisera raised against polypeptide components of antigenically related rat Sertoli cell secretory protein S70 and S45-S35 heterodimeric protein were used to identify antigenic sites in rat testis during spermatogenesis. Immunofluorescence, immunoperoxidase and immunogold electron-microscopic methods have shown that all antisera recognize immunoreactive sites in the acrosome of developing spermatids. Apical cytoplasmic regions of Sertoli cells in close association with bundles of developing spermatids displayed an immunoreactive product. The principal piece of the developing tail of maturing spermatids immunostained with antisera to Sertoli cell secretory S45-
\end{abstract}

S35 heterodimeric protein, displayed characteristic apical-to-distal immunoreactive gradient patterns before acquiring uniform immunoreactivity at completion of maturation. Immunogold electron microscopy demonstrated that outer dense fibres were the predominant immunoreactive site. Results of this work, together with previous immunoblotting and immunofluorescent data, demonstrate that both Sertoli cell secretory proteins and components of the acrosome and tail of developing spermatids and epididymal sperm share antigenic homology.

Key words: outer dense fibres, immunogold electron microscopy, spermiogenesis.

\section{Introduction}

At the end of the second meiotic division, haploid spermatids, connected by cytoplasmic bridges and surrounded by Sertoli cell cytoplasm, undergo a differentiation process known as spermiogenesis (for a review, see Setchell, 1978; Fawcett, 1986). This process involves, among other features, progressive nuclear condensation and chromatin structural changes (Kierszenbaum \& Tres, 1975), and the development of the acrosome and tail. Products derived from the Golgi apparatus accumulate gradually in the acrosome, which spreads over part of the nuclear surface. Tail development includes the formation of the axoneme followed by the organization of longitudinally oriented, periaxonemal outer dense fibres extending distally from the head-connecting piece junction. The developmental pattern of outer dense fibres during spermiogenesis has been reported (rat; Irons \& Clermont, 1982a). The temporal synthesis of sperm tail proteins has been studied by intratesticular injection of radiolabelled precursors and recovery of sperm from epididymis at defined time intervals (mouse; O'Brien \& Bellvé, 1980; rat; Vera et al. 1987). Yet the site of their synthesis has not been identified.

We have reported that S70 and S45-S35 heterodimeric protein, two acidic glycoproteins secreted by rat Sertoli cells (DePhilip \& Kierszenbaum, 1982; Kierszenbaum et al. 1986a), become prominent during testicular development in correlation with the onset of spermiogenesis and then acquire a spermatogenic stage-dependent secretory pattern (Shabanowitz et al. 1986; Kierszenbaum et al. 1987). These two Sertoli cell secretory glycoproteins were purified by high-performance liquid chromatography to determine their role during spermatogenesis (Abdullah et al. 1988). In the native state, S70 and S45-S35 heterodimeric protein have binding affinity for each other and appear antigenically related (Abdullah et al. 1988). Polyclonal antisera raised against polypeptide components of these two glycoproteins cross-react in immunoblotting experiments with outer dense fibres extracted from sperm tail (Abdullah et al. 1988). Immunoblotting findings were correlated with the immu- 
nofluorescence, immunoperoxidase and immunogold electron-microscopic localization of antigenic sites in developing spermatids and epididymal sperm described in this paper.

\section{Materials and methods}

Indirect immunofluorescence and immmunoperoxidase of plastic-embedded specimens

Small pieces of testes and terminal segments of the epididymal duct $\left(0 \cdot 5 \mathrm{~cm}^{3}\right)$ from sexually mature rats $(70-100$ days old, Charles River Laboratories, Wilmington, MA) were fixed in $2 \%$ paraformaldehyde in phosphate-buffered saline (PBS) containing $5 \mathrm{~mm}-\mathrm{MgCl}_{2}$ for $2 \mathrm{~h}$ at room temperature. Specimens were rinsed in PBS for 2-4h, dehydrated first in ethanol $70 \%(2 \mathrm{~h})$ and then in ethanol $95 \%(2 \mathrm{~h})$. Tissues were embedded in Historesin (LKB, Bromma, Sweden) according to manufacturer's recommendations, polymerized at room temperature, and sectioned with glass knives. Plastic sections (about $1-2 \mu \mathrm{m}$ thick) were floated on a drop of distilled water placed on a microscope slide and dried at $60^{\circ} \mathrm{C}$. Sections were etched with xylene for $30 \mathrm{~min}$, rinsed in PBS (2 changes of $5 \mathrm{~min}$ each), $2.5 \%$ trypsin (Sigma, St Louls, MO) in PBS $\left(30 \mathrm{~min}\right.$ at $\left.37^{\circ} \mathrm{C}\right)$, and rinsed in PBS ( 2 changes of $5 \mathrm{~min}$ each).

Tissue sections were immunoreacted with polyclonal antisera to Sertoli cell secretory proteins (working dilution $1: 10$ to $1: 100$ for immunofluorescence and immunoperoxidase) for $24 \mathrm{~h}$ at $4^{\circ} \mathrm{C}$ in a moist chamber. Specimens were rinsed in PBS (3 changes of $2 \mathrm{~min}$ each) and then reacted with second antibody, $1 \mathrm{~h}$ at room temperature in a moist chamber. Second antibodies (Cappel, Malvern, PA) were goat anti-rabbit IgG conjugated with fluorescein isothiocyanate $(1: 10$ to $1: 100)$ and rabbit antihorseradish peroxidase $(1: 100)$ followed by treatment with freshly prepared diamınobenzidine tetrahydrochloride $\left(7.5 \mathrm{mg} \mathrm{ml}^{-1}\right)$ solution with $0.002 \% \mathrm{H}_{2} \mathrm{O}_{2}$ for $10 \mathrm{~min}$. Specimens were mounted with Elvanol (for immunofluorescence) or Permount (for immunoperoxidase).

Spermatogenic cells were collected from spermatogenic stage-specific seminiferous tubules (identıfied by transillumination; Parvınen, 1982; DePhilip et al. 1983) by squeezing out cells on a glass coverslip using a small roller. Cells were fixed in $3.7 \%$ formaldehyde in PBS for $15 \mathrm{~min}$ and processed for indirect immunofluorescence using polyclonal or monoclonal antibody as reported (Kierszenbaum et al. 1986b). Fig. 1 demonstrates that antiserum raised to protem $\mathrm{S} 70$ cross-reacts strongly with S35 and less strongly with S45 (lane 1). Ant1S45-S35 serum cross-reacts strongly with the putative antigens and S70 (lane 2). Antiserum to S45 recognizes S45 and S70 but not S35 (lane 3). Antiserum to S35 cross-reacts with S35 and S70 but not S45 (lane 4). Additional data on the biochemical characterization of antigens and antibodies have been reported (Abdullah et al. 1988). In some experiments, cells were double labelled with antisera to Sertoli cell secretory proteins and monoclonal antibody to beta-tubulin (a generous gift from Dr Edward D. Salmon; Scholey et al. 1984) to determine a spatial relationship between axonemal and para-axonemal immunoreactive sites of spermatıd tails. Ant1-beta-tubulin was localized with goat anti-mouse $\mathrm{IgG}-$ rhodamme.

\section{Immunogold electron microscopy}

Testis specimens were fixed in $2 \%$ paraformaldehyde and $1 \%$ glutaraldehyde in $0.1 \mathrm{M}$-phosphate buffer, $\mathrm{pH} 7 \cdot 0\left(2 \mathrm{~h}\right.$ at $\left.4^{\circ} \mathrm{C}\right)$, rinsed in $0.1 \mathrm{M}$-phosphate buffer containing $10 \%$ sucrose $(2 \mathrm{~h}$ at $4^{\circ} \mathrm{C}$ ), and dehydrated in ethanol $50 \%$ to $100 \%$ at room temperature. Specimens were directly embedded in epoxy resin

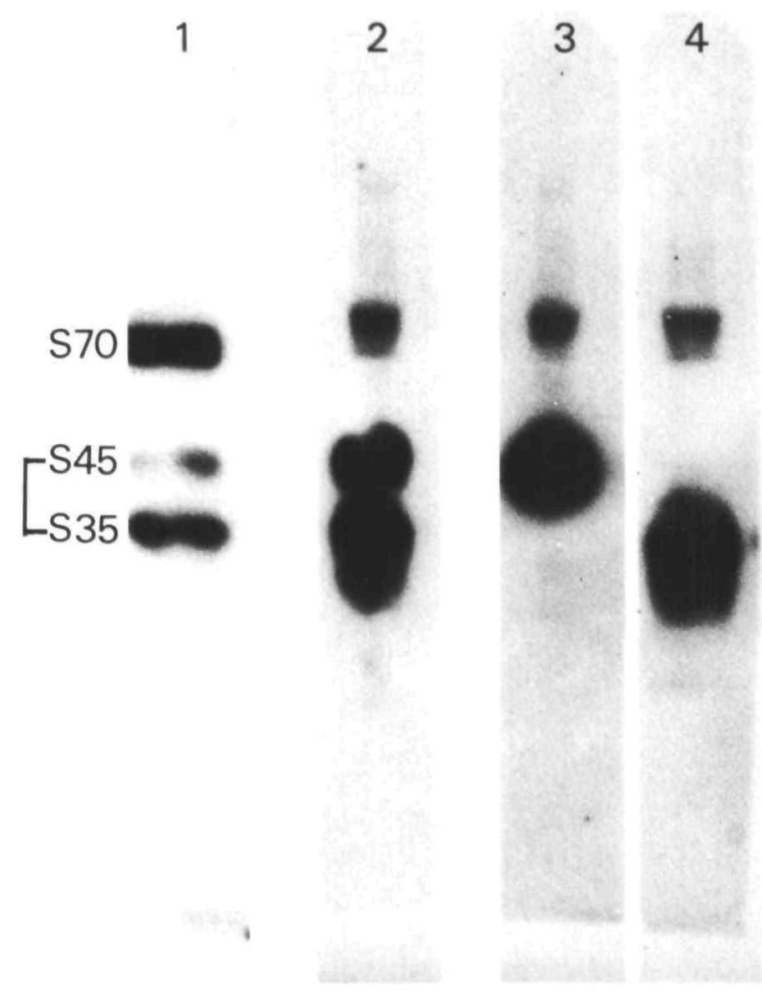

Fig. 1. Immunoblotting characterization of antisera against S70 (lane 1), S45-S35 (lane 2), S45 (lane 3), and S35 (lane 4). Lanes contain concentrated Sertoli cell secretory proteins accumulated in culture medium (lane 1,80 $\mathrm{kg}$; lanes $2-4,90 \mu \mathrm{g}$ each). Dilution of primary antiserum was $1: 100$. Bound antibody was visualized with radioiodinated Protem A $\left(1 \times 10^{5} \mathrm{cts} \mathrm{min}^{-1} \mathrm{ml}^{-1}\right)$ and autoradiography (24 h exposure time). The position of $\mathrm{S} 70$ and polypeptide components of $\$ 45-S 35$ heterodimeric protein are indicated at the left. For additıonal technical details, see Abdullah et al. (1988).

(EMBED 812, Polysciences, Warrington, PA) and polymerized according to manufacturer's recommendations. Thin sections (gold interference colour) were collected on uncoated nickel grids $(150 \mathrm{mesh})$ and placed for $15 \mathrm{~min}$ on a drop of $0.1 \%$ bovine serum albumin (BSA) in PBS to reduce non-specific protein adsorption. Polyclonal antisera to S70, S45, S35 and S45-S35 heterodimeric protein were diluted in $0.1 \%$ BSA in PBS and sections immunoreacted for $2 \mathrm{~h}$ at room temperature (dilutions of $1: 1000$ to $1: 2000$ ). After rinsing in PBS for $15 \mathrm{~min}$, grids were floated for $1 \mathrm{~h}$ on a drop of gold conjugated to rabbit IgG (Auroprobe EM GAR G15 $(15 \mathrm{~nm})$ from Janssen Life Sciences (supplied by Ted Pella, Tustin, CA)) diluted in $0.1 \%$ BSA in PBS $(1: 100)$. Specimens were rinsed in PBS for $15 \mathrm{~min}$, in distilled water for $1 \mathrm{~min}$, and stained with $1 \%$ uranyl acetate in distilled water $(15-20 \mathrm{~min})$. Sections were examined in a JEOL 100-CX transmission electron microscope. Controls included increasing dilutions of first and second antibody and omission of first antibody.

Triton-dithiothreitol extraction of epididymal spem Sperm collected from cauda epididymidis were washed three times in PBS containıng $0.5 \%$ BSA (by centrifugation $(500 \mathrm{~g}$ ) and resuspension). Sperm were extracted in $1 \%$ Triton X-100, $2 \mathrm{~mm}$-dithiothrettol, $100 \mathrm{~mm}-\mathrm{NaCl}$, and $25 \mathrm{~mm}-$ Tris $\cdot \mathrm{HCl}$ $(\mathrm{pH} 9 \cdot 0)$ for $15 \mathrm{~min}$. Sperm were washed twice in $100 \mathrm{~mm}-\mathrm{NaCl}$ in $25 \mathrm{~mm}$-Tris $\cdot \mathrm{HCl}(\mathrm{pH} 7 \cdot 5)$, resuspended in PBS-0.5\% BSA, 
and incubated for $15 \mathrm{~min}$ in diluted rabbit antısera raised against Sertoli cell secretory proteins. Samples were overlaid on PBS containing $5 \% \mathrm{BSA}$ and centrifuged $(480 \mathrm{~g} 10 \mathrm{~min})$. The pellet was resuspended in PBS- $0.5 \%$ BSA and incubated for $15 \mathrm{~min}$ with goat anti-rabbit $\mathrm{IgG}$-fluorescein. The sample was overlaid on PBS-5\% BSA, centrifuged $(480 \mathrm{~g}, 10 \mathrm{~min})$, and resuspended in PBS- $0.5 \%$ BSA. A drop of the sample $(10 \mu \mathrm{l})$ was placed on a microscope slide, covered with a glass coverslip, and examined by fluorescence microscopy.

\section{Results}

\section{Acrosomal immunoreactive sites}

Thin sections of rat testis embedded in a water-soluble medium (Historesin) were used to localize antigenic sites by indirect immunofluorescence and immunoperoxidase using polyclonal antibodies raised against Sertoli cell secretory proteins. A similar embedding and immunostaining procedure was used for the localization of intermediate filament proteins in cocultured peritubular and Sertoli cells using a monoclonal antibody (Ueda $e t$ al. 1988). This procedure provides satisfactory tissue preservation, excellent resolution, and permits combined phase-contrast/immunufluorescence microscopy for identification of seminiferous epithelial cell types. Fig. 2A-C shows the immunofluorescent localization of acrosomal antigenic sites in cross-sections of seminiferous tubules of different spermatogenic stages. Immunoreactive sites were detected with anti-S70 serum, known to cross-react with the polypeptide components of S45-S35 heterodimeric protein in addition to S70 (Fig. 1; and Abdullah et al. 1988). Acrosomal localization was also observed with antisera raised against S45-S35 heterodimeric protein, and to polypeptide components S45 and S35 (see below). Acrosomal inmunoreactivity is of practical significance because it permits identification of each stage of rat spermatogenesis (Leblond \& Clermont, 1952). Fig. 2D demonstrates both acrosomal immunoperoxidase reactivity and a granular product in apical regions of Sertoli cell cytoplasm surrounding bundles of elongating spermatids (stage XII). In the peroxidase technique, no staining was detected at dilutions of $1: 10000$ or higher. Therefore, positive staining depended on the primary antiserum only, and not on any of the subsequent staining reagents or on endogenous peroxidase. Indirect immunofluorescence detected similar immunoreactive granules in cytoplasmic regions adjacent to developing spermatids (Fig. 3A).

At high magnification, acrosomal immunoreactivity detected by indirect immunofluorescence appears as a string of granules (stage VI, Fig. 3A). Immunogold electron microscopy confirms the acrosomal localization of immunoreactive product sharing antigenic homology with Sertoli cell secretory proteins (Fig. 3B,C). A significant observation is the absence of immunoreactivity in the Golgi apparatus from which acrosomal components are known to arise.

In more advanced steps of spermiogenesis (spermatogenic stages X-XII, Fig. 4A-D), acrosomal immunoreactive patterns correlate with known acrosomal morphogenic events occurring in spermatids during the elongation of the head. Coexistent with head elongation, the immunoreactivity of the developing tail is gradually detected with antisera to Sertoli cell secretory proteins. Both acrosomal and tail immunoreactivity are better visualized in whole spermatids extruded from seminiferous tubules identified by transillumination as spermatogenic stage-specific (Fig. 4B-D) than in sections of plastic-embedded testicular specimens (Fig. 2B).

\section{Tail immunoreactive sites}

Spermatids collected from seminiferous tubules stages IX-I and immunoreacted with either anti-S45-S35, anti-S45 or anti-S35 serum display tails with a striking banding pattern along the principal piece, extending in a gradient fashion distally from the annulus region toward the terminal portion (Fig. $5 \mathrm{~A}-\mathrm{C}$ ). Anti-S70 serum does not yield this characteristic banding pattern. Immunoreactive bands appear as blocks of parallel elements of variable length (Fig. $5 \mathrm{C}$ ). Some asynchrony can be detected in both banding and gradient patterns in tails of spermatids collected from a single spermatogenic stage (Fig. 5B). Upon completion of spermiogenesis (stage VIII-IX), the middle piece of the tall appears slightly immunoreactive while the immunoreactivity of the principal piece is strong and diffuse (Fig. 5D). This segmentspecific tail immunoreactivity was not apparent in double-immunostaining experiments using an antibody to beta-tubulin to detect microtubules of the axoneme (Fig. 5D,E),

Immunogold electron microscopy was carried out to identify tail components in epididymal sperm that could account for the immunofluorescent patterns. Fig. 5F-H demonstrates that tail immunoreactivity is restricted to outer dense fibres and acrosome (Fig. 5G). To facilitate the identification of immunofluorescent reactivity in outer dense fibres, epididymal sperm were extracted with Triton-dithiothreitol (DTT) to remove cell membranes and fray outer dense fibres of the middle piece (Olson et al. 1976) before immunostaining with antisera to Sertoli cell secretory proteins. Frayed outer dense fibres, extending from the connecting piece to the annulus, show immunoreactivity. The principal piece appears less immunoreactive and the head more immunoreactive after Triton-DTT extraction (Fig. 5I).

\section{Discussion}

Studies have been carried out to identify antigenic sites in rat testis recognized by polyclonal antibodies raised against Sertoli cell secretory proteins. These studies were considered of interest because the secretion of S70 and S45-S35 heterodimeric protein: (1) is not relevant during early postnatal stages of testicular development; (2) is prominent during the onset of spermiogenesis; (3) is expressed cyclically in a stage-dependent manner (Shabanowitz et al. 1986; Kierszenbaum et al. 1987); and (4) S45-S35 heterodimeric protein is released apically by polarized Sertoli cells cultured on a microporous substrate, whereas S70 is detected in both basal and apical compartments (Ueda et al. 1988). The vectorial release 

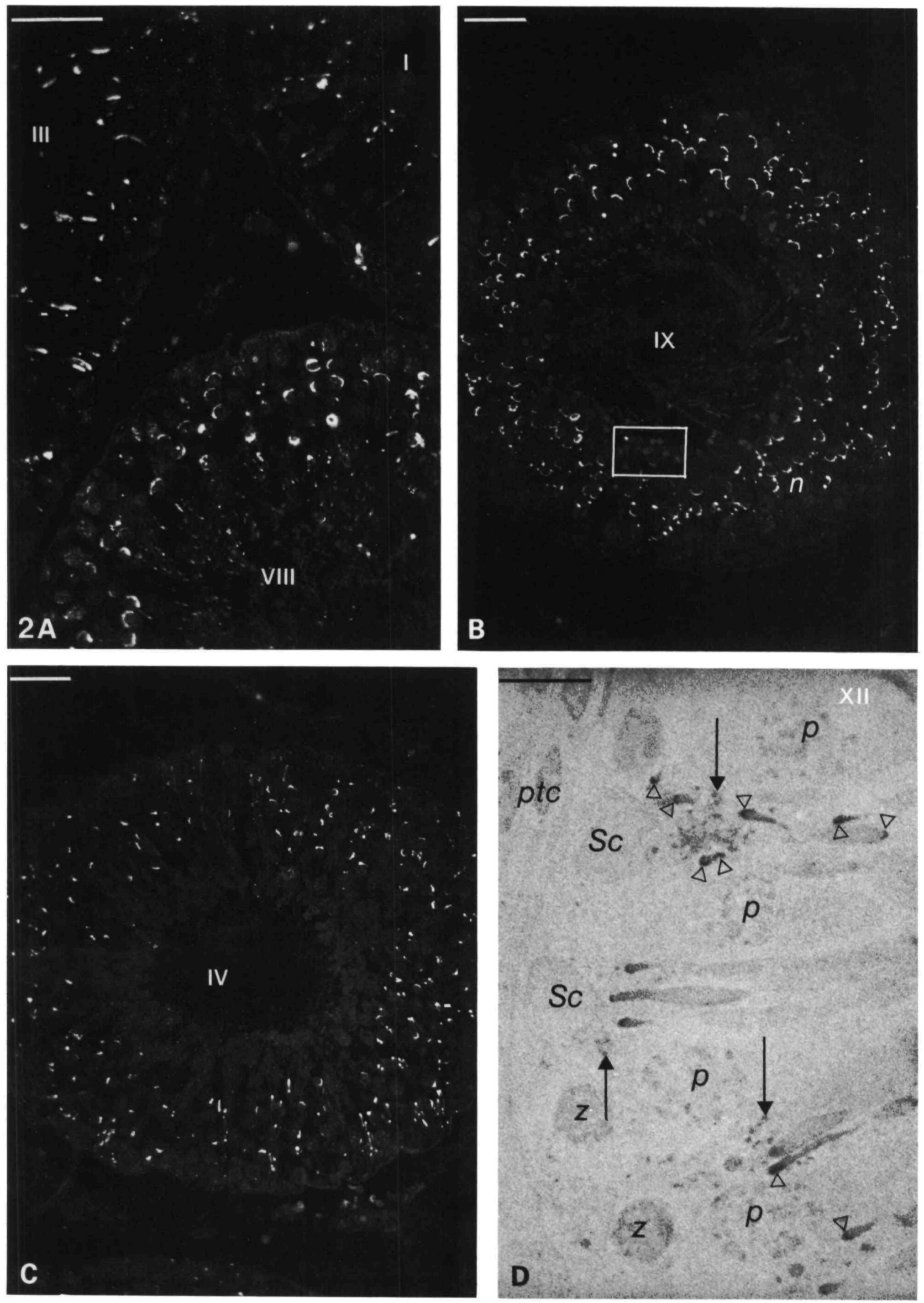

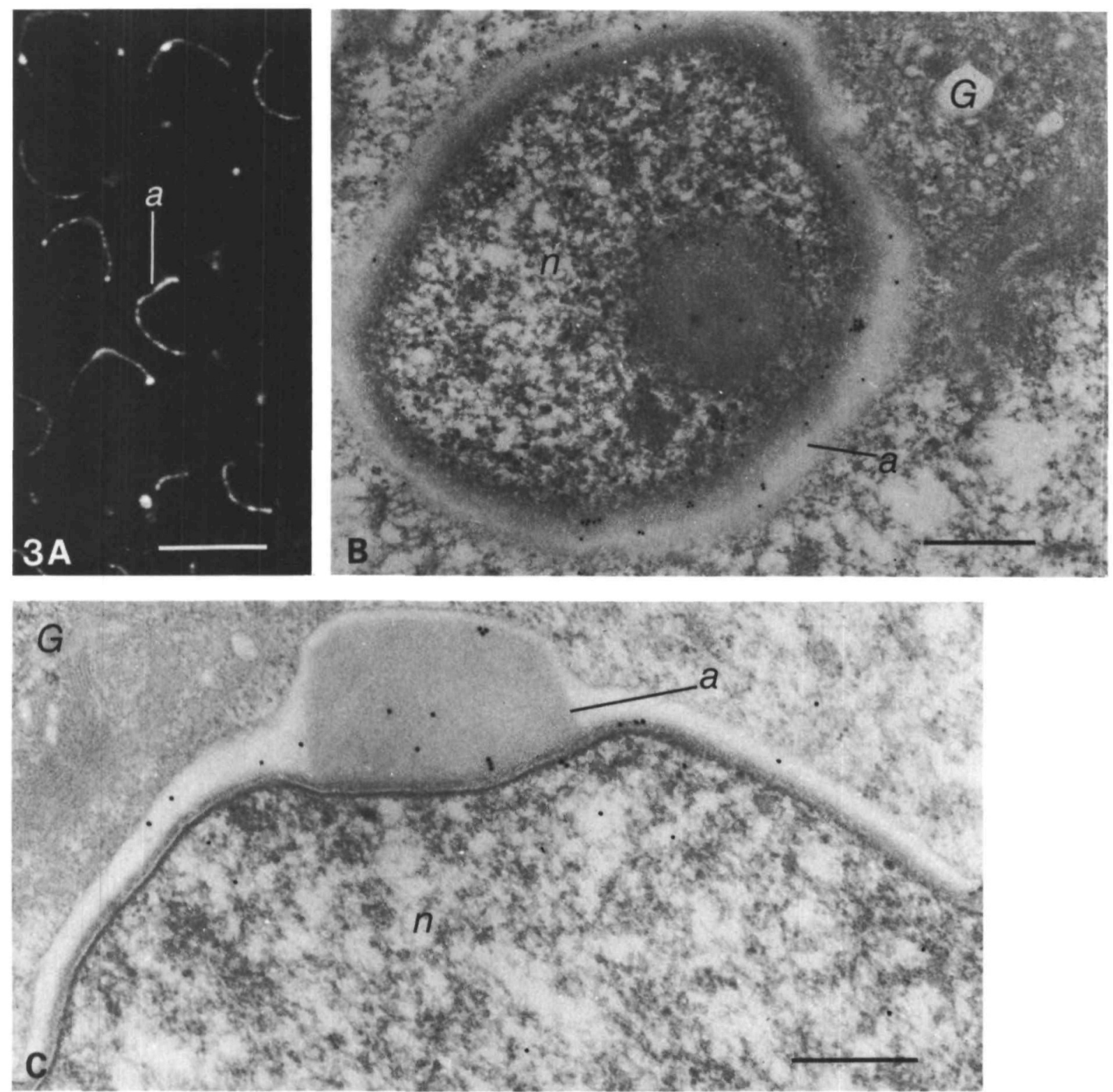

Fig. 3. Indirect immunofluorescence (A) and immunogold electron microscopy (B-C) of acrosomal immunoreactivity detected with anti-S70 serum. A. Granular immunoreactivity in crescent-shaped acrosome $(a)$ of developing spermatids during spermatogenic stage VI. Granules distributed between spermatids may reflect cytoplasmic immunoreactive sites. B. Acrosomal $(a)$ immunoreactivity observed in a cross-section of a spermatid (step 6). The Golgi $(G)$ apparatus is almost devoid of gold particles (primary antiserum, 1:1000; gold $(15 \mathrm{~nm})-\operatorname{IgG}$ conjugate, $1: 100) ; n$, nucleus. C. Acrosomal $(a)$ immunoreactivity in a sagittal view of a spermatid (step 5). The Golgi $(G)$ apparatus appears free of gold particles (primary antiserum, 1:2000; gold-IgG conjugate, $1: 50 ; n$, nucleus). Bars: A, $20 \mu \mathrm{m} ; \mathrm{B}, \mathrm{C}, 5 \mu \mathrm{m}$.

Fig. 2. Indirect immunofluorescence $(A-C)$ and immunoperoxidase (D) localization of immunoreactive sites in rat testis using ant1-S70 serum. A. Acrosomal immunoreactive patterns in seminiferous tubules during stages I, III and VIII of rat spermatogenesis. B. Stage IX. The box identifies residual bodies corresponding to the previous generation of spermatids released into the seminiferous tubular lumen. C. Stage IV characterized by the presence of two generations of spermatids (steps 4 and 17). D. Stage XII characterized by zygotene $(z)$ and pachytene $(p)$ spermatocytes. Cytoplasmic regions of Sertoli cells $(\mathrm{Sc})$ in contact with deeply inserted spermatids (step 12) display granular immunoreactivity (arrow). Arrowheads identify the immunoreactive acrosome. $p t c$, peritubular cells. Bars: A-C, $50 \mu \mathrm{m} ; \mathrm{D}, 20 \mu \mathrm{m}$. 

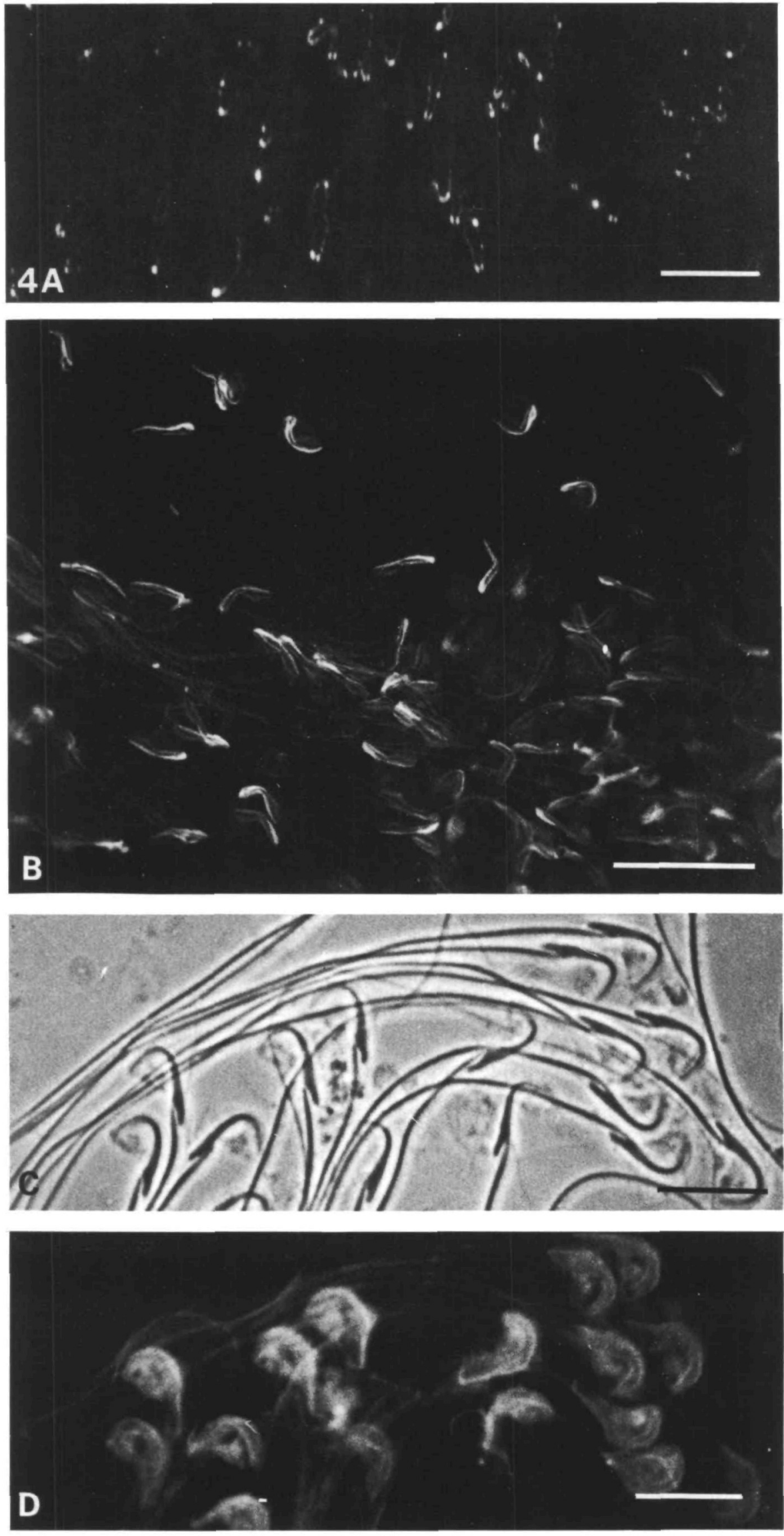

A. L. Kierszenbaum et al.
Fig. 4. Indirect immunofluorescence localization of acrosomal and tail immunoreactivity in seminiferous epithelium ( $A$, stage $X$, anti-S70 serum) and whole spermatids extruded from seminiferous tubules stages $\mathrm{X}-\mathrm{XII}$ (B,D, anti-S35 serum). A. Granular immunoreactivity in the acrosome of elongating spermatid heads. B. Sickle-shaped acrosomes over elongating nuclei. Tails are moderately mmunoreactive. C-D. Phase-contrast microscopy (C) and corresponding indirect immunofluorescence of spermatids step 11 (D) showing both acrosomal and tail immunoreactıvity. Bars: A, C, D , $20 \mu \mathrm{m} ; \mathrm{B}, 60 \mu \mathrm{m}$. 

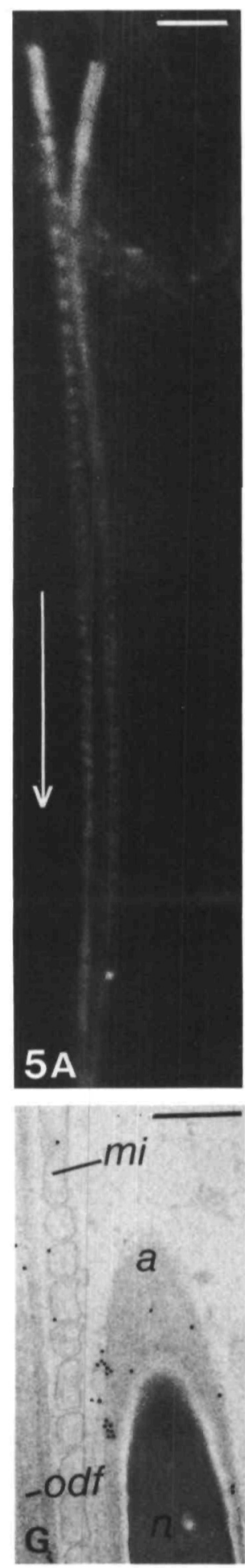
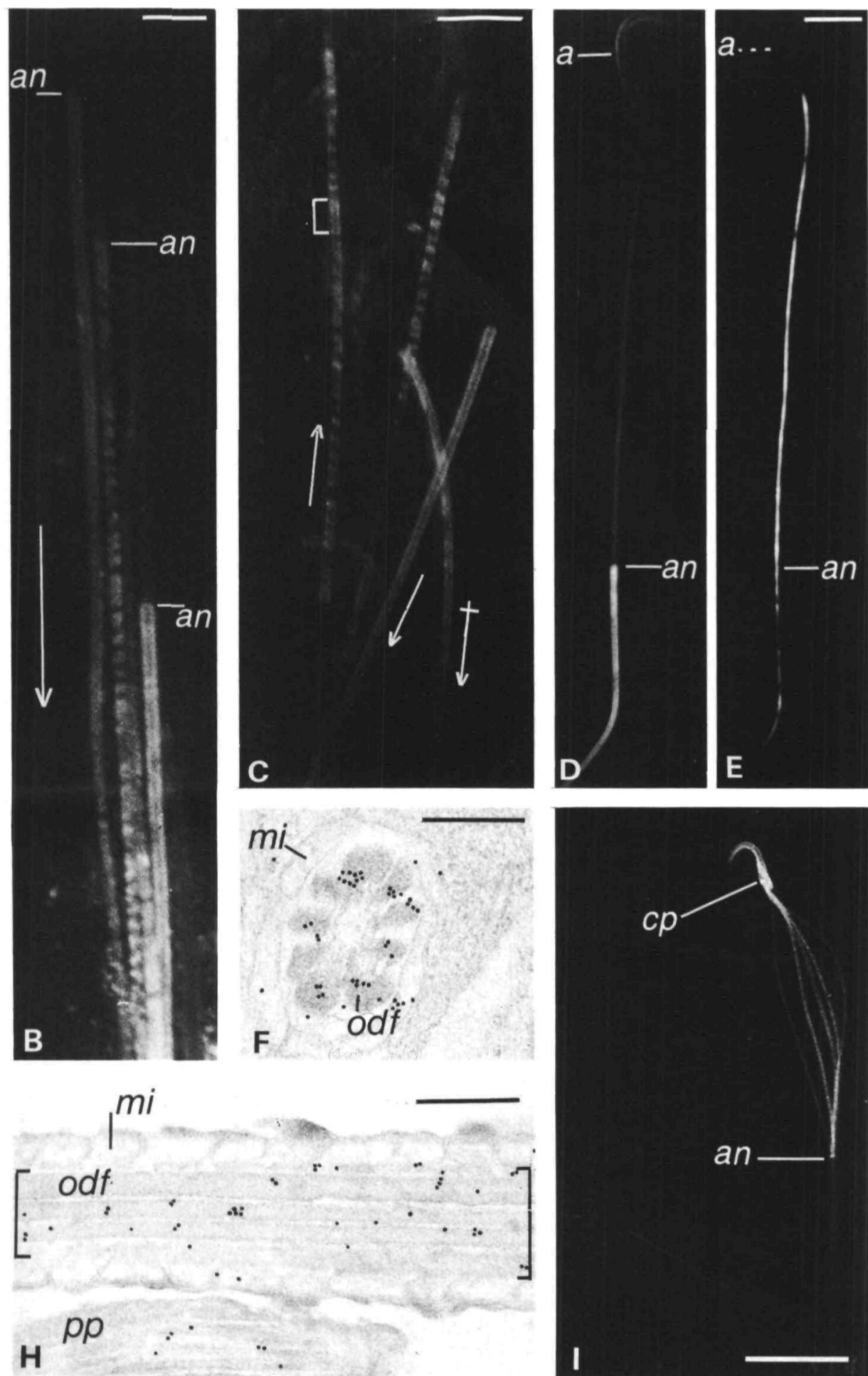

Fig. 5. Temporal study of tail immunofluorescent reactivity during the final steps of rat spermiogenesis $(A-E, I)$ and immunogold electron microscopy of epididymal sperm $(\mathrm{F}-\mathrm{H})$. A-D,I. Immunostained with anti-S45 serum; E, anti-betatubulin; F, H, anti-S45/S35 serum; G, anti-S70 serum. The direction of the arrow in A-C indicates the apical-to-distal orientation of the developing tails. $a$, acrosome; $a n$, annulus at the junction of middle-principal piece of the tail; $c p$, connecting piece at the head-tail junction. The crossed arrow in $\mathrm{C}$ denotes an example of the proximal-to-distal progression of the banding pattern. The bracket in C identifies an immunoreactive band. D-E. Mature spermatid (step 19) double-immunostained with anti-S45 serum (D) and anti-beta-tubulin (E). F-H. Immunogold electron microscopy showing immunogold product on outer dense fibres (odf, denoted between brackets in $\mathrm{H}$ ) and acrosome $(a)$. mi, mitochondria of the middle piece region of sperm tail; $p p$, principal piece region of sperm tail. I. Triton-DTT extracted sperm with immunoreactive outer dense fibres fraying from the middle piece region of the tail. Bars: $A, B, F, G, H, 10 \mu \mathrm{m} ; C-E, 10 \mu \mathrm{m} ; \mathrm{I}, 30 \mu \mathrm{m}$. 
of S45-S35 heterodimeric protein by Sertoli cells could represent an in vivo correlate of the utilization of this protein by adluminally located spermatids in the seminiferous tubule (Ueda et al. 1988).

The visualization of immunoreactivity by indirect immunofluorescence, immunoperoxidase and immunogold electron microscopy demonstrated a temporal sequence during spermiogenesis at defined subcellular localization sites. Two aspects are of interest: (1) the localization of antigenic sites in the acrosome but not in the Golgi apparatus; and (2) the apical-to-distal progression of immunoreactive sites during tail development.

Rat spermiogenesis is subdivided into 19 steps on the basis of morphological changes in the acrosome detected by its positive reactivity for periodic acid-Schiff reagents (Leblond \& Clermont, 1952). The 19 steps are grouped in four distinct phases: Golgi phase (steps 1-3), cap phase (steps 4-7), acrosome phase (steps 8-14) and maturation phase (steps 15-19). During the Golgi and cap phases of acrosomal development, the Golgi apparatus contributes glycoproteins to the acrosome as shown by cytochemical and autoradiographic approaches (Susi et al. 1971; Mollenhauer et al. 1976; Clermont et al. 1981; Tang et al. 1982; Clermont \& Tang, 1985). We have visualized acrosomal immunoreactivity throughout spermiogenesis in sections of plastic-embedded testis processed for indirect immunofluorescence and immunoperoxidase. In addition, our immunogold electronmicroscopic studies show that antisera raised to S70, S45, $\mathrm{S} 35$, and to a mixture of $\mathrm{S} 45-\mathrm{S} 35$ polypeptide components of major glycoproteins secreted by Sertoli cells, recognize antigenic sites in the acrosome but not in the closely associated Golgi apparatus. This observation suggests that the antigenic material detected in the developing acrosome by these antisera may not be derived from the Golgi apparatus. The close apposition of Sertoli cell surfaces to the plasma membrane of spermatogenic cells, including spermatids, raises the possibility that Sertoli cell secretory products may be transported to developing spermatogenic cells. In fact, a vesicular transport mechanism of substances from rat Sertoli cells to adjacent spermatids has been claimed (Morales \& Clermont, 1982). The precise pathway of Sertoli cell secretory proteins during spermatogenesis is the subject of continuing studies in our laboratory.

The morphogenesis of the outer dense fibres during rat spermiogenesis has been studied by electron microscopy and autoradiography (Irons \& Clermont, 1982a). Outer dense fibre material appears during step 8 of spermiogenesis in association with the axoneme. During steps 9-14, outer dense fibres increase in length in a proximalto-distal direction, from the middle piece to the principal piece of the tail. During steps 15-16, rudimentary outer dense fibres increase in diameter and assume the characteristic morphology of mature outer dense fibres observed in sperm. Our indirect immunofluorescence studies of whole spermatids (steps 9-14) extruded from seminiferous tubules by mechanical means demonstrate identical timing and structural sequence in the deposition of immunoreactivity along the principal piece of the devel- oping tail. Immunogold electron microscopy of epididymal sperm shows that antisera raised against Sertoli cell secretory proteins are associated with outer dense fibres. Immunoblotting studies have shown an antigenic homology between extracted outer dense fibres of sperm tails and Sertoli cell secretory proteins (Abdullah et al. 1988). This antigenic homology was antiserum-dependent since anti-S70 serum recognized five of the seven major sperm tail polypeptides, whereas anti-S45 and anti-S35 sera cross-reacted with all seven polypeptides with different degrees of immunological reactivity (Abdullah et al. 1988). It is possible that differences in cross-reactivity and accessibility of immunoglobulin to antigenic binding sites may account for immunofluorescent segment regionalization observed during tail morphogenesis. In fact, outer dense fibres of Triton-DTT-extracted sperm acquire strong immunoreactivity along the middle piece of the tail, whereas untreated sperm are moderately immunoreactive. In addition, immunogold electron microscopy shows that outer dense fibres are immunoreactive at the middle piece region.

Our immunocytochemical and immunoblotting findings were unexpected since the general view is that proteins comprising the bulk of the acrosome and outer dense fibres are synthesized by spermatids during spermiogenesis (Burgos \& Fawcett, 1955; Sandoz, 1972; Susi et al. 1971; Mollenhauer et al. 1976; Tang et al. 1982; Irons \& Clermont, 1982a,b). The temporal synthesis of sperm tail proteins has been studied after intratesticular injection of $\left[{ }^{3} \mathrm{H}\right]$ leucine (mouse; O'Brien \& Bellvé, 1980; Vera et al. 1987), $\left[{ }^{3} \mathrm{H}\right]$ proline and $\left[{ }^{3} \mathrm{H}\right]$ cystine (rat; Irons \& Clermont, 1982a,b). Radiolabelled proteins were either fractionated days later when spermatozoa were recovered from the epididymal duct at defined time intervals (O'Brien \& Bellvé, 1980; Vera et al. 1987) or traced in the testis by autoradiography (Irons \& Clermont, $1982 a, b)$. Because of the cell heterogeneity of the seminiferous epithelium, intratesticular radiolabelling is a valuable approach for determining the temporal appearance of tail proteins during spermiogenesis but may not be sufficient for defining the precise cell origin of precursor proteins.

A precise interpretation of our immunocytochemical and immunoblotting results is difficult at the present time. Our observations raise two possibilities: (1) the uptake and processing of Sertoli cell secretory proteins by developing spermatids; and (2) the antigenic homology between Sertoli cell secretory proteins and protein components of the acrosome and outer dense fibres. An experimental analysis of these two possibilities is being carried out in our laboratory using molecular cloning techniques.

Hiroshi Ueda was a recipient of a Fogarty International Fellowship (1F05 TW0381). Liu Ping was supported by a grant from The Rockefeller Foundation to Laura L. Tres. Munir Abdullah was supported in part by a grant from The Andrew W. Mellon Foundation to The Laboratories for Reproductive Biology. Additional support was provided by NIH grant HD11884 to A. L. Kierszenbaum. 


\section{References}

Abdullah, M., Tres, L. L., Ueda, H., Hu, P.C. \& Kierszenbaum, A. L. (1988). Antigenic homology between rat sperm tail polypeptides and Sertoli cell secretory proteins. Molec. Cell. Biochem. (in press).

Burgos, M. W. \& FAwCETt, D. W. (1955). Studies on the fine structurc of the mammalian testis. I. Differentiation of spermatids in the cat (Felix domestica). J. biophys. biochem. Cytol. 1, 287-300

Clermont, Y., Lallu, M. F. \& Rambourg, A. (1981).

Ultrastructural localization of nicotinamide adenine dinucleotıde phosphatase (NADPase), thiamine pyrophosphatase (TPPase) and cytidine monophosphatase (CMPase) in the Golgi apparatus of early spermatids of the rat. Anat. Rec. 201, 613-622.

Clermont, Y. \& TANG, X. M. (1985). Glycoprotem synthesis in the Golgi apparatus of spermatıds during spermıgencsis of the rat. Anat. Rec. 213, 33-43.

DePhilip, R. M. \& Kierszendaum, A. L. (1982). Hormonal regulation of protein synthesis, secretion, and phosphorylation in cultured rat Sertoli cells. Proc, natn. Acad. Sci. U.S.A. 79 , $6551-6555$.

DePhilip, R. M., Tres, L. \& Kierszenbaum, A. L. (1983). Stagespecific protein synthesis during rat spermatogenesis. Expl Cell Res. 142, 489-494.

FAWCETT, D. W. (1986). Male reproductive system. In Textbook of Histology, 11th edn, pp. 796-850. Philadelphia: W. B. Saunders.

Irons, M. J. \& Clermont, Y. (1982a). Formation of the outer dense fibers during spermiogenesis in the rat. Anat. Rec. 202, 463-471.

Irons, M. J. \& ClermonT, Y. (1982b). Kinetics of fibrous sheath formation in the rat spermatid. Am. Y. Anat. 165, 121-130.

Kierszenbaum, A. L., Abdullah, M., Ueda, H. \& Tres, L. L. (1987). Spermatogenesis in vitro: searching for in vivo correlates. In Regulation of Ovarian and Testicular Function (ed. V. B. Mahesh, D. S. Dhindsa, E. Anderson \& S. P. Kalra), pp. 535-560. New York: Plenum.

Kierszenbaum, A. L., Crowell, J. A., Shabanowitz, R. B., DePhilip, R. M. \& Tres, L. L. (1986a). Protein secretory patterns of rat Sertoli and peritubular cells are influenced by culture conditions. Biol. Reprod. 35, 239-251.

Kierszendaum, A. L., Crowell, J. A., Shabanowitz, R. B., Smith, E. P., Sphuill, W. A. \& Tres, L. L. (1986b). A monoclonal antibody recognizes a form of intermediate filament protem in rat Sertoli cells that is not present in seminiferous peritubular cells. Biol. Reprod. 35, 227-238.

Kierszenbaum, A. L. \& Tres, L. L. (1975). Structural and transcriptional features of the mouse spermatıd genome. $\%$. Cell
Biol. 65, 258-270.

Leblond, C. P. \& Clermont, Y. (1952). Spermiogenesis of rat, mouse, hamster, and guinea pig as revealed by the "periodic acid-fuchsin sulfurous acid" technique. Am. J. Anat. 90, 167-215.

Mollenhauer, H. H., Hass, B. S. \& Morre, D. J. (1976). Membrane transformations in Golgi apparatus of rat spermatıds. A role for thick cisternae and two classes of coated vesicles in acrosome formation. Y. Microscopie Biol. Cell 27, 33-36.

Morales, C. \& Clermont, Y. (1982). Evolution of Sertol cell processes invading the cytoplasm of rat spermatids. Anat. Rec. 203 233-244.

O'Brien, D. A. \& Bellve, A. R. (1980). Protein constituents of the mouse spermatozoon. II. Temporal synthesis during spermatogenesis. Devl Biol. 75, 405-418.

Olson, G. E., Hamilton, D. W. \& Fawcett, D. W. (1976). Isolation and characterization of the fibrous sheath of rat epıdidymal spermatozoa. Biol. Reprod. 14, 517-530.

Parvinen, M. (1982). Regulation of the seminiferous epithelium. Endocr. Rev. 3, 404-417.

SANDOZ, D. (1972). Evolution des ultrastructures au cours de la formation de l'acrosome de spermatozoide chez la souris. 7 . Microsc. 9, 535-558.

Scholey, J. M., Neighbors, B., Mcintosh, J. R. \& Salmon, E. D. (1984). Isolation of microtubules and a dynein-like MgATPase from unfertilized sea urchin eggs. J. Biol. Chem. 259, 6516-6525. SetChell, B. P. (1978). Spermatogenesis. In The Mammahan Testis, pp. 181-232. Ithaca: Cornell University Press.

Shabanowttz, R. B., DePhilip, R. M., Crowell, J. A., Tres, L. L. \& Kierszenbaum, A. L. (1986). Temporal appearance and cyclic behavior of Sertoli cell-specific secretory proteins during the development of the rat seminiferous tubule. Biol. Reprod. 35, $745-760$.

Susi, F. R., Leblond, C. P. \& Clermont, Y. (1971). Changes in the Golgi apparatus during spermiogenesis in the rat. Am. Y. Anat. $130,251-278$

Tang, X. M., Lalli, M. F. \& Clermont, Y. (1982). A cytochemical study of the Golgi apparatus of the spermatıd during spermogenesis in the rat. Am. J. Anat. 163, 283-294.

Ueda, H., Tres, L. L. \& Kierszenbaum, A. L. (1988). Culture patterns and sorting of rat Sertoli cell secretory protenns. 7. Cell Sct. 89, 175-189.

VerA, J. C., Brito, M. \& Burzio, L. O. (1987). Biosynthesis of rat sperm outer dense fibers durıng spermıogenesis. In vivo incorporation of $\left[{ }^{3} \mathrm{H}\right]$ leucine into the fibrillar complex. Biol. Reprod. 36, 193-202.

(Received 19 April 1988 - Accepted 2 June 1988) 
